\title{
A ALCA e o setor privado brasileiro: dois casos exemplares
}

\author{
Antônio Carlos Lessa*
}

O movimento de expansão regional e mundial de muitas das grandes empresas latino-americanas mostra o quanto elas avançaram na grande ebulição que tomou conta do mundo empresarial nos últimos anos, movidas pela disputa por mercados cada vez mais integrados. A crescente movimentação que se tem verificado no cenário empresarial internacional nos últimos anos que pelos anúncios de grandes fusões, aquisições, incorporações e associações, contemplando a totalidade ou partes de grandes empresas - começa a caracterizar o ânimo com que as corporações transnacionais rearticulam as suas operações em nível mundial, tornando-as mais competitivas e ágeis para responder aos desafios de um mundo de negócios verdadeiramente global. Desse modo, a diversificação de investimentos em atividades e/ou regiões, ora concentrando seus esforços em "core business" ou em seus mercados principais, são apenas algumas das táticas que têm sido implementadas nos dias de hoje para permitir a adaptação das grandes empresas ao ritmo de negócios característico da globalização, aprofundando os seus vínculos com o mercado internacional.

Duas empresas brasileiras são sempre lembradas quando se pensa nas estratégias de pre- paração dos grandes atores econômicos brasileiros para a atuação em um mercado de proporções hemisféricas, tendo-se em conta as possibilidades de expansão de negócios que surge com a criação da Área de Livre Comércio das Américas - ALCA: a Aços Gerdau e a Petrobrás.

O grupo siderúrgico Gerdau iniciou a sua expansão internacional ainda no início dos anos oitenta, quando o mercado doméstico brasileiro parecia não ser mais suficiente para absorver novas ampliações de oferta, uma vez que a empresa atendia sozinha à pouco mais da metade do consumo local, largamente caracterizado pela presença avassaladora da produção das então empresas estatais que, inclusive, foram alvo imediato da fúria expansionista do grupo Gerdau no sentido de consolidar a sua posição no mercado brasileiro.

Do ponto de vista de sua estratégia internacional, seguindo a tendência de muitos outros grupos de igual porte, que ao depararem-se com a tendência de concentração dos seus setores de atividades em mãos de um número reduzido de jogadores dotados de capacidade de atuação mundial, a Gerdau expandiu-se para outros mercados pela compra de outras empresas, firmando o foco de sua internacionalização na região que 
Ihe parecia com maior potencial de crescimento - ou seja, o hemisfério. Atualmente a Gerdau é a maior fabricante de aços da América Latina, com faturamento de US $\$ 2,26$ bilhões em 1999, figurando entre as 25 maiores siderúrgicas do mundo. O resultado da sua opção preferencial pelas Américas ganha os contornos de um mapa desenhado a partir das possibilidades de expansão nos diferentes mercados nacionais - a empresa tem duas fábricas na Argentina, uma no Chile, duas no Canadá, quatro nos EUA e uma no vizinho Uruguai.

O processo de internacionalização da Petrobrás é bem mais antigo que o da Gerdau há que se lembrar o fato de que, pela própria natureza de país importador de petróleo, é de longa data que a empresa mantém relacionamento comercial com países fornecedores de todos os continentes (Arábia Saudita, Irã, Iraque, Rússia, Inglaterra, Noruega, EUA, Venezuela, Argentina, Angola, e Nigéria sendo alguns exemplos de grandes fornecedores de óleo bruto para o Brasil). A isto se soma um intercâmbio técnico-científico tradicionalmente muito denso e a atuação de suas empresas subsidiárias Interbrás (trading criada para comercializar produtos fabricados no Brasil em contrapartida às compras de petróleo no exterior), e Braspetro (para empreendimentos de engenharia e prospecção no exterior, em países como Iraque e Angola).

A atuação internacional do grupo Petrobrás ganhou novo ritmo e passou a obedecer a nova estratégia a partir do início do processo de abertura do setor petróleo no Brasil, no qual a expan-

\section{"A atuação}

internacional do

grupo Petrobrás

ganhou novo ritmo e

passou a obedecer a

nova estratégia a partir

do início do processo

de abertura do setor

petróleo no Brasil, no

qual a expansão

internacional passou a

ser entendida como

uma necessária

contrapartida para a

maior exposição que a

empresa brasileira terá

à concorrência

estrangeira." são internacional passou a ser entendida como uma necessária contrapartida para a maior exposição que a empresa brasileira terá à concorrência estrangeira, em especial, de grupos empresariais norte-americanos. Esta questão assume relevância especial quando se considera o esforço que a empresa brasileira demonstrou para adaptar a sua estratégia internacional e firmar o seu foco na área geográfica na qual apresenta melhores condições para uma performance vencedora - no caso, no hemisfério em geral, e na América Latina em particular. Com efeito, considerando a posição geográfica que a holding Petrobrás ocupa, fatores logísticos e a sua identificação histórico-cultural, a definição da expansão da sua atividade internacional deveria naturalmente encontrar o seu eixo no fortalecimento da sua presença na América Latina, e prioritariamente na América do Sul. A caracterização da atuação da Petrobrás na integração hemisférica é dada por três fatores importantes, quais sejam, a entrada de concorrentes estrangeiros no mercado brasileiro, o desequilíbrio no escoamento da sua produção (considerando a atrofia existente na relação entre o nível de produção e o nível de distribuição, uma vez que a empresa produz mais derivados do que é capaz de comercializar por canais próprios) e a liberalização da importação de derivados.

Há que se recordar que se encontram em andamento (ou já estão implantadas) importantes parcerias com empresas de países da região que se inscrevem no âmbito da estratégia que a empresa traçou para ter uma melhor inserção na 
ALCA, a saber: a) na Bolívia - criação da Petrobrás Bolívia (PEB), com a intensificação das atividades de exploração, e sobretudo com a conclusão e início da exploração do gasoduto Brasil-Bolívia, ao que se soma a aquisição de refinarias, a implantação de rede de postos de serviços e a comercialização direta de derivados e lubrificantes; b) na Argentina - criação da Petrobrás Argentina (PAR), na qual se efetivou a troca de ativos com a Repsol/YPF, o adensamento na participação no sistema de transporte por gasodutos e igualmente a exploração, produção, e comercialização direta de derivados e lubrificantes; c) nos EUA - criação da Petrobrás América (PAI) para a exportação de gasolina e a exploração direta de petróleo no Golfo do México; d) no Paraguai, Uruguai, Colômbia, Trinidad e Tobago, Equador e Peru, a holding tem empreendido iniciativas que possibilitem a comercialização dire- ta de derivados, combustíveis e lubrificantes e a exploração e produção direta; e) na Venezuela, país rapidamente se transformou em grande fornecedor de petróleo e derivados para o Brasil.

Para além do hemisfério, a holding Petrobrás segue estratégia idêntica e, mesmo antes do início do processo de abertura do setor petróleo no Brasil, a empresa vem mantendo conversações com a quase totalidade das empresas internacionais de petróleo, discutindo possíveis áreas ou projetos de interesse comum. Tendo isto em vista, a empresa definiu em seu planejamento estratégico o incremento de suas atividades internacionais tendo sempre como prioridade o seu fortalecimento regional nos mercados da América do Sul, notadamente na Argentina e na Bolívia, no Caribe e no sul dos EUA. Por essa razão, o projeto lançado em dezembro de 2000 (e imediatamente abandonado diante da reação

\title{
Assine a Revista Brasileira de Política Internacional - RBPI
}

\author{
Assinatura Anual (2 Edições) \\ Pessoa Física: $R \$ 40,00$ - Pessoa Jurídica: $R \$ 60,00$ - Exterior: US\$30,00 \\ Envie o cupom de assinatura e a forma de pagamento escolhida \\ (cheque ou cópia de depósito bancário) para: \\ Instituto Brasileiro de Relações Internacionais - IBRI \\ Caixa Postal 4400 - 70919-970 - Brasília - DF - Brasil - Telefax: (55 61) 3071655 -E-mail: ibri@unb.br
}

\section{Cupom de Assinatura:}

Nome:

Instituição:

CPF:

Endereço:

Bairro:

CEP: Cidade: UF:

Tel.: (

) Fax.: ( E-mail:

País: 
vociferante de setores importantes da opinião pública brasileira) de mudar o nome da empresa para Petrobrax, atendendo à necessidade de firmar uma marca mais palatável para o cliente "estrangeiro", não era de todo absurdo.

De muitos casos de empresas brasileiras, os exemplos da Gerdau e da Petrobrás são certamente aqueles que respondem mais diretamente aos desafios endógenos de crescimento dos negócios, e que encontram uma instrumentalidade certa para o processo de regionalização em sua estratégia de internacionalização. Vê-se, entretanto, que esta dimensão já não é tão clara em muitas outras áreas, uma vez que boa parte das empresas de muitos setores, especialmente o industrial, não estão prontas para responder de modo tão positivo ao desafio da integração hemisférica, adotando muitas vezes aprioristicamente postu- ras reativas, que acabam inclusive por contaminar o debate sobre os ganhos e perdas da criação da ALCA para o Brasil.

De fato, a perspectiva dos atores privados é bastante heterogênea, a depender não apenas do porte dos negócios envolvidos, a considerarse que certamente a visão das pequenas e médias empresas contrasta com a dos grandes jogadores, como também dos setores de atividades, e neste caso, os exemplos da Petrobrás e da Gerdau, em sua visão extremamente positiva das possibilidades que a constituição da ALCA trazem para as suas atividades, não é partilhada pela maioria dos setores da economia brasileira... Pelo que se vê, com certeza ainda temos muito o que aprender com as experiências dos dois grandes campeões brasileiros.

${ }_{0} 00$

+1044 Meridiano 47

Boletim de Análise de Conjuntura em Relações Internacionais

\section{ISSN 1518-1219}

Editor: Antonio Jorge R. da Rocha

Editor-adjunto: Antônio Carlos Lessa

Conselho Editorial:

Alcides Costa Vaz, Amado Luiz Cervo, Estevão R. Martins, Francisco Doratioto, José Flávio S. Saraiva, Luiz Fernando Ligiéro, Argemiro Procópio Filho, Virgílio Caixeta Arraes.

Diagramação e Editoração Eletrônica: Samuel Tabosa de Castro - 9956-1028 